\title{
Metachronous adrenal metastasis from operated contralateral renal cell carcinoma with adrenalectomy and iatrogenic Addison's disease
}

\author{
Hakan Ozturk, MD; ${ }^{*}$ Serap Karaaslan, $M D^{+}$ \\ "Department of Urology, School of Medicine, Sifa University, Izmir, Turkey; 'Department of Pathology, School of Medicine, Sifa University, Izmir, Turkey
}

Cite as: Can Urol Assoc J 2014;8(9-10):e744-8. http://dx.doi.org/10.5489/cuai.2120

Published online October 22, 2014.

\section{Abstract}

Metachronous adrenal metastasis from contralateral renal cell carcinoma (RCC) surgery is an extremely rare condition. latrogenic Addison's disease occurring after metastasectomy (adrenalectomy) is an even rarer clinical entity. We present a case of a 68-year-old male with hematuria and left flank pain 9 years prior. The patient underwent left transperitoneal radical nephrectomy involving the ipsilateral adrenal glands due to a centrally-located, $75-\mathrm{mm}$ in diameter solid mass lesion in the upper pole of the left kidney. The tumour lesion was confined within the renal capsule, and the histopathological examination revealed a Fuhrman nuclear grade II clear cell carcinoma. The patient underwent transperitoneal right adrenalectomy. The histopathological examination revealed metastasis of clear cell carcinoma. The patient was diagnosed with iatrogenic Addison's disease based on the measurement of serum cortisol levels and the adrenocorticotropic hormone (ACTH) stimulation test, after which glucocorticoid and mineralocorticoid replacement was initiated. The patient did not have local recurrence or new metastasis in the first year of the follow-up. The decision to perform ipsilateral adrenalectomy during radical nephrectomy constitutes a challenge, and the operating surgeon must consider all these rare factors.

\section{Introduction}

Renal cell carcinomas (RCC) exhibit a high potential of metastasis in nearly all organs. RCCs can metastasize to the lungs $(50 \%-60 \%)$, liver $(30 \%-40 \%)$, bone $(30 \%-40 \%)$, and less commonly to the brain (5\%). ${ }^{1}$ The rate of ipsilateral adrenal metastasis of RCC ranges from $1.1 \%$ to $10 \%$ (mean $3 \%$ ), and contralateral metastasis rarely occurs with an approximate rate of $0.7 \% .^{2}$ The reports on bilateral adrenal metastasis of RCC are limited to 20 cases in the literature. ${ }^{3}$ In general, one-fourth of patients with RCC develop metastasis during their lives. Surgical intervention in such metastases is known to increase overall survival. ${ }^{1}$

\section{Case report}

\section{Clinical features}

A 68-year-old male was admitted 9 years prior due to macroscopic hematuria with gross blood clots and left flank pain. The biochemical tests were normal. Ultrasonography and computed tomography showed a $75 \times 60 \times 70$-mm heterogeneous solid mass located in upper pole of the left kidney, and the patient underwent transabdominal radical nephrectomy involving ipsilateral adrenal tissue with a prediagnosis of renal cell carcinoma (RCC). The pathology report was nonmetastatic ipsilateral adrenal clear cell carcinoma, Fuhrman grade II with a tumour diameter $75 \mathrm{~mm}$. The pathological examination revealed yellow-orange tumour lesion in the upper pole of the left kidney, measuring $75 \mathrm{~mm}$ in diameter and spreading to the renal pelvis. The tumour was confined within the renal capsule. There was no bleeding or necrosis. The examination showed tumour cells with alveolar structure containing clear cytoplasm and small-moderate size nucleolus (Fig. 1). The tumour was evaluated as Fuhrman nuclear grade II. The immunohistochemical examination showed positive staining for CD 10 and RCC (Fig. 2, Fig. 3), and the pathological examination report indicated clear cell carcinoma.

The tumour was staged as T2aNOMO according to TNM classification. The patient was placed on a follow-up program according to the follow-up system of European Urology Association (EAU). The follow-up examinations performed on the eighth year revealed progressively growing contralateral metachronous metastasis in the right adrenal gland. Magnetic resonance Imaging (MRI) and Positron emission tomography (PET)/computed tomography (CT) confirmed the presence of a solitary metastatic lesion. T2-weighted MRI showed a heterogeneous hyperintense mass lesion with contrast uptake in the right adrenal tissue measuring $60 \times 38 \mathrm{~mm}$ in size (Fig. 4, Fig. 5). PET/CT showed a metastatic lesion in the right adrenal tissue measuring $60 \times 43 \times 34 \mathrm{~mm}$, with a marked 18F-fluorodeoxyglucose 


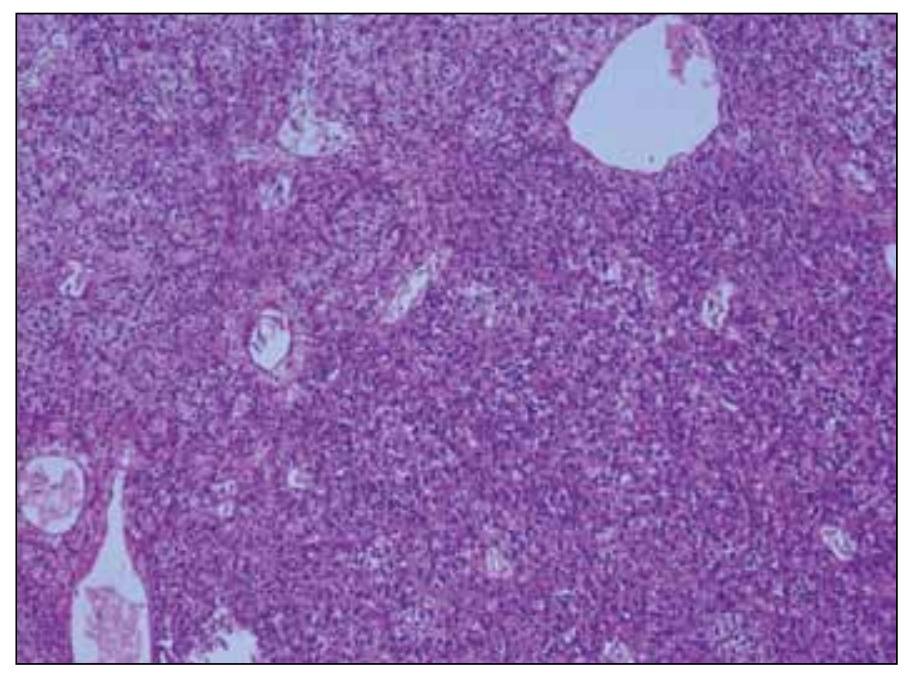

Fig. 1. Hematoxilyn-eosin staining demostrating (H\&E 100).

(FDG) uptake and maximum standardized uptake value of 6.3. The lesion was hormonally inactive. Metastasectomy (adrenalectomy) was planned, and the patient was assessed by the department of endocrinology with a multidisciplinary approach with regard to the potential presence of Addison's disease (frozen section was malignant). We tallied the results of the biochemical tests before metastasectomy (Table 1). Mineralocorticoid and glucocorticoid replacement was performed during adrenalectomy. The postoperative serum cortisol level was $0.805 \mathrm{ug} / \mathrm{dL}$, and adrenocorticotropic hormone (ACTH) stimulation test was performed using intravenous $250 \mu \mathrm{g}$ synthetic ACTH. There was no increase in the blood cortisol levels at 30 and 60 minutes. The diagnosis of iatrogenic Addison's disease was confirmed. In the postoperative period, biochemical parameters were normal except hyponatremia (sodium $130 \mathrm{mmol} / \mathrm{L}$ ).

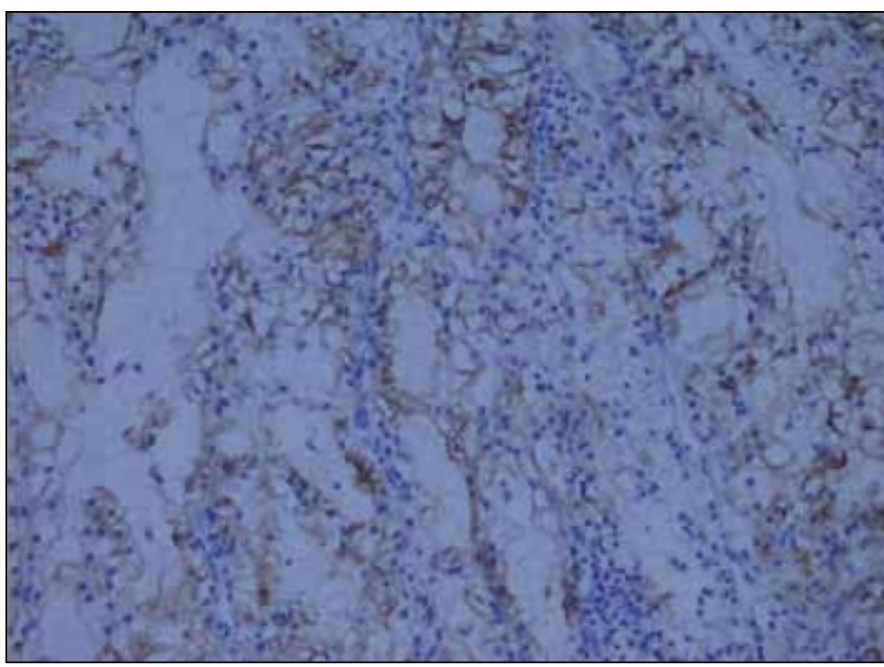

Fig. 3. Immunohistochemistry showing, RCC $(+)$, $[R C C \times 200]$

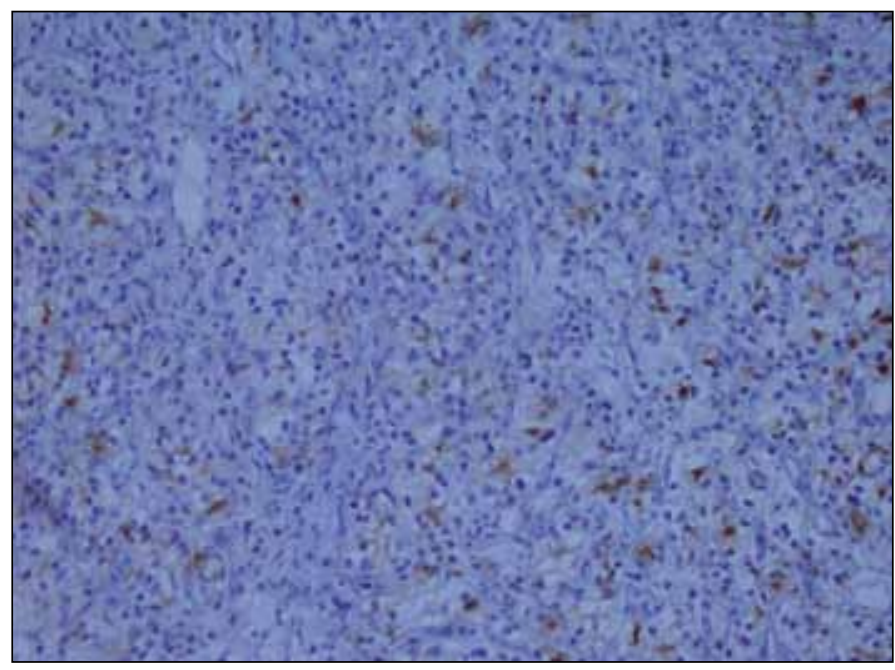

Fig. 2. Immunohistochemistry showing, CD10 (+), [CD10 ×200].

\section{Immunohistopathological findings}

Pathological examination was performed on the adrenalectomy material, measuring $75 \times 60 \times 33 \mathrm{~mm}$ in size. A yellow-orange tumour lesion measuring $62 \times 50 \times 27 \mathrm{~mm}$ in size was observed adjacent to the adrenal tissue and covered with a thin capsule. The areas of clear RCC were observed adjacent to the adrenal tissue with typical features (Fig. 6). A higher magnification showed tumour cells with alveolar structure containing clear cytoplasm and small size nucleolus (Fig. 7). The tumour was evaluated as Fuhrman nuclear grade I. The immunohistochemical examination showed positive staining for CD10 and RCC (Fig. 8, Fig. 9).

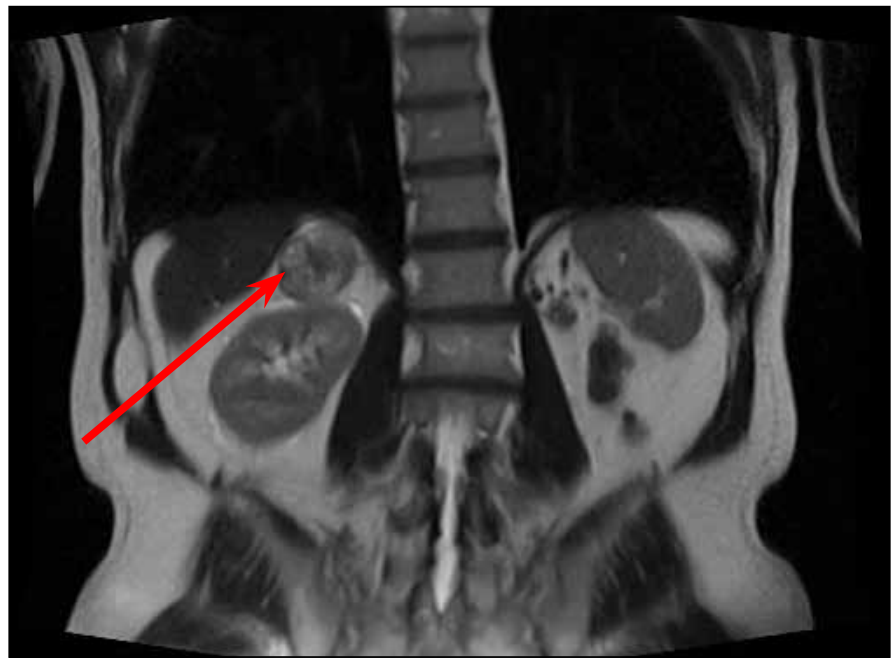

Fig. 4. Magnetic resonance imaging (MRI) and PET/CT confirmed the presence of a solitary metastatic lesion. T2-weighted MR images showed a heterogeneous hyperintense mass lesion with contrast uptake in the right adrenal tissue measuring $60 \times 38 \mathrm{~mm}$ in size. 


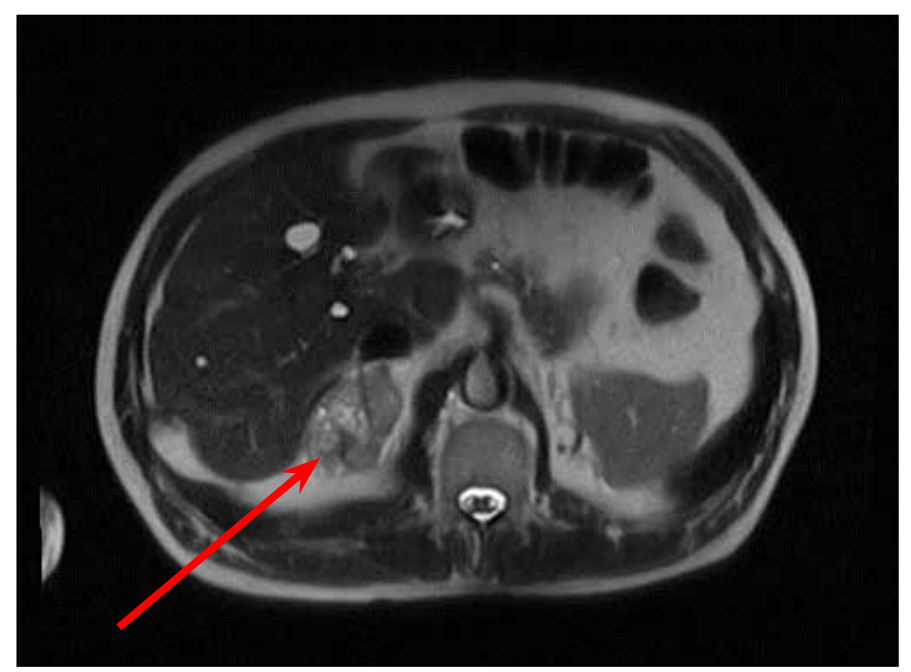

Fig. 5. Magnetic resonance Imaging (MRI) and PET/CT confirmed the presence of a solitary metastatic lesion. T2-weighted MR images showed a heterogeneous hyperintense mass lesion with contrast uptake in the right adrenal tissue measuring $60 \times 38 \mathrm{~mm}$ in size.

\section{Treatments and survival}

One month after performing adrenalectomy, the patient presented with fatigue, weakness, palpitation, sweating, difficulty in swallowing, excessive water intake, and frequent urination. The results of the biochemical tests are tallied in Table 2. The patient was prescribed lifelong use of prednisolone, hydrocortisone, and fludrocortisone. The 1 -year postoperative MRI and PET/CT imaging did not show recurrence or metastasis (Fig. 10).

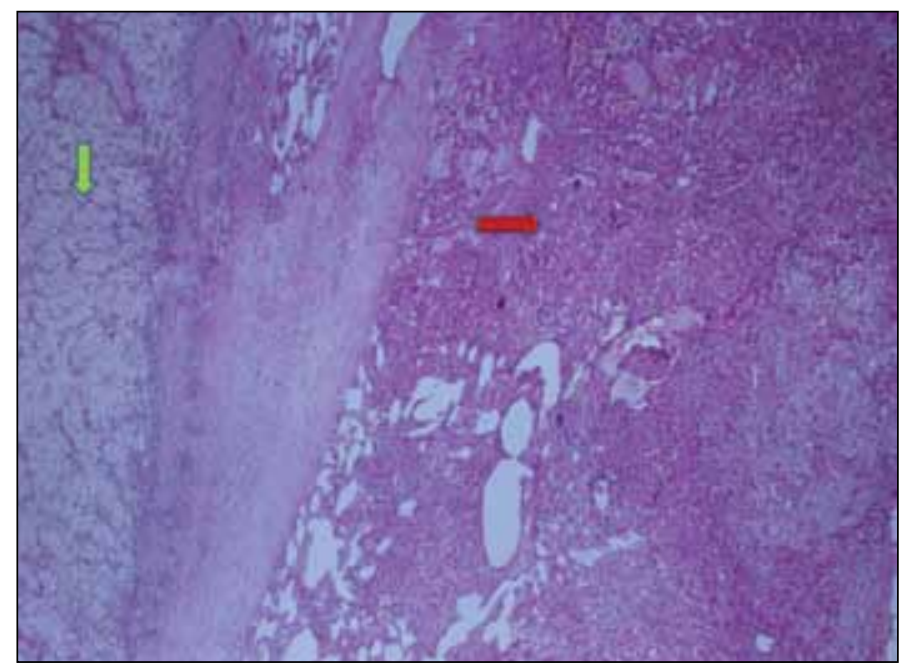

Fig. 6. Hematoxylin-eosin staining demonstrating $(H \& E \times X 40)$ (red arrow: normal adrenal tissue, green arrow: typical area of renal cell carcinoma adjacent to the adrenal tissue), (metastatic mass).

\begin{tabular}{|c|c|}
\hline Glucose & $84 \mathrm{mg} / \mathrm{dL}$ \\
\hline Creatinine & $1.2 \mathrm{mg} / \mathrm{dL}$ \\
\hline Urea & $28 \mathrm{mg} / \mathrm{dL}$ \\
\hline White blood cells & $5.11 \times 10^{3} / \mu \mathrm{L}$ \\
\hline $\mathrm{Hgb}$ & $14.7 \mathrm{~g} / \mathrm{dL}$ \\
\hline Eosinophil & $0.28 \times 10^{3} / \mu \mathrm{L}$ (normal) \\
\hline Sodium & $136 \mathrm{mmol} / \mathrm{L}$ \\
\hline Potassium & $4.5 \mathrm{mmol} / \mathrm{L}$ \\
\hline Chloride & $103 \mathrm{mEq} / \mathrm{L}$ \\
\hline Calcium & $8.6 \mathrm{mg} / \mathrm{dL}$ \\
\hline Cortisol & $15 \mu \mathrm{g} / \mathrm{dL}$ \\
\hline
\end{tabular}

AST-ALT-ALP-GGT were within normal ranges.

\section{Discussion}

A routine ipsilateral adrenalectomy is not recommended in radical nephrectomy. ${ }^{4,5}$ The reason is that there is no difference in overall survival. Only 3 of 2065 patients who underwent concurrent ipsilateral adrenalectomy had direct invasion of the adrenal gland by RCC or renal cell carcinoma metastasis. Even in the presence of suspicious adrenal lesions detected by imaging methods, only $13 \%$ of these contained cancer. ${ }^{6}$ However in a retrospective study, Kobayashi and colleagues demonstrated that there is no statistically significant difference in disease-specific survival in patients undergoing ipsilateral simultaneous adrenalectomy and patients with adrenal-sparing radical nephrectomy due to RCC. ${ }^{7}$ The adrenal metastasis from RCC is not a rare clinical entity. In general, a metastasis rate up to $10 \%$ was found in some series. However, the development of iatrogenic Addison's disease following the late occurrence of contralateral adrenal metastasis and metastasectomy (adrenalectomy) is rare.

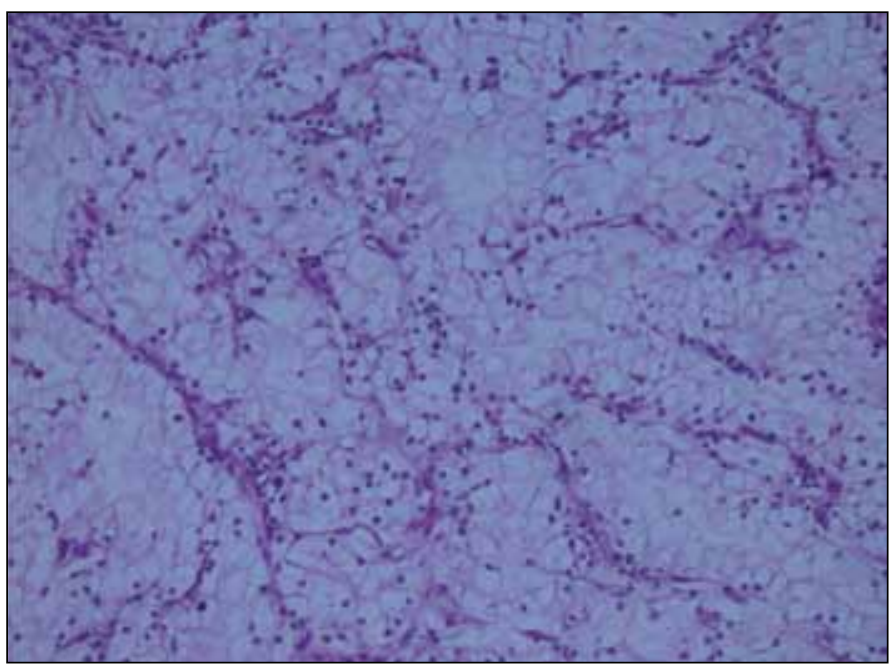

Fig. 7. Hematoxilyn-eosin staining demostrating, $(H \& E \times 200)$, metastatic mass. 


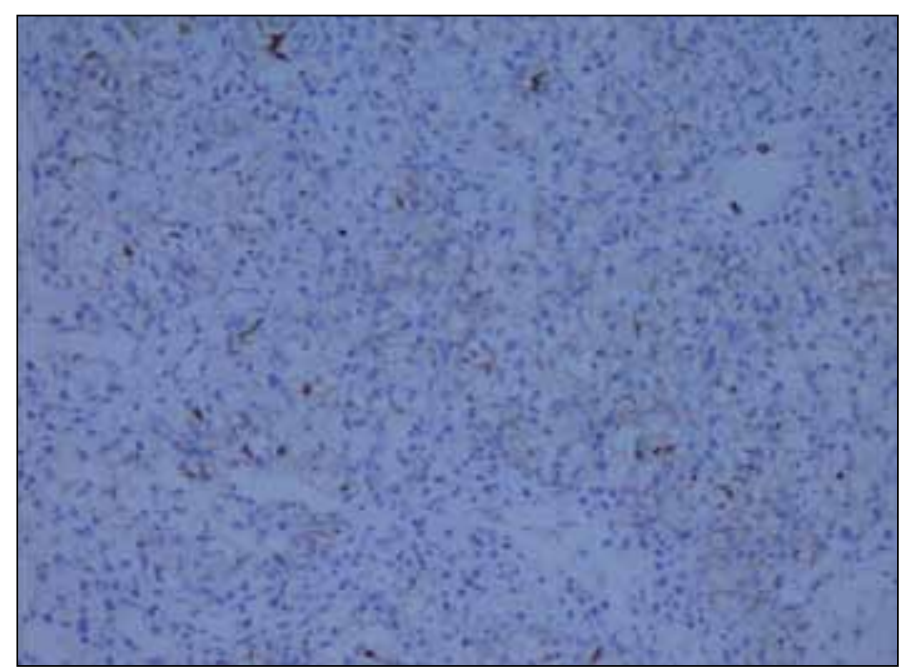

Fig. 8. Immunohistochemistry showing, CD10 (+), (CD10 ×200), metastatic mass.

The development of iatrogenic Addison's disease indicates the vital importance of adrenalectomy performed as part of the surgical approach to primary renal cancer.

Currently, ipsilateral adrenalectomy is recommended in the presence of upper pole tumours, or of metastasis detected by $\mathrm{CT}$ and/or MRI, or of a renal mass measuring larger than $8 \mathrm{~cm}$. Apart from this, adrenalectomy has no contribution to survival. ${ }^{8}$ Some risk factors have been identified in terms of adrenal metastasis. Large renal masses, upper pole tumours, tumour arising from the left kidney, and multifocal tumours are risk factors for adrenal metastasis. However, it must be recognized that small lower pole tumours may also show ipsilateral and contralateral metastasis. ${ }^{9,10}$ The mean time to the development of a metachronous metastasis was 52.3 months. The adrenal lesions detected in patients who were placed on follow-up after performing operation for RCC requires verification. Hormonal investigation is recommended in patients who underwent surgery due to RCC and

\begin{tabular}{lc}
\hline $\begin{array}{l}\text { Table 2. Results of the biochemical tests } \mathbf{1} \text { month after } \\
\text { performing adrenalectomy }\end{array}$ \\
\hline Glucose & $122 \mathrm{mg} / \mathrm{dL}$ \\
Creatinine & $1.5 \mathrm{mg} / \mathrm{dL}$ \\
Urea & $51 \mathrm{mg} / \mathrm{dL}$ \\
White blood cells & $6.55 \times 103 / \mu \mathrm{L}$ \\
Hgb & $13.0 \mathrm{~g} / \mathrm{dL}$ \\
Eosinophil & $0.02 \times 103 / \mu \mathrm{L}$ (normal) \\
Sodium & $130 \mathrm{mmol} / \mathrm{L}$ (hyponatremia) \\
Potassium & $5.1 \mathrm{mmol} / \mathrm{L}$ \\
Chloride & $107 \mathrm{mEq} / \mathrm{L}$ \\
Calcium & $8.8 \mathrm{mg} / \mathrm{dL}$ \\
Cortisol & $0.449 \mu \mathrm{g} / \mathrm{dL}(6.2-19.4 \mathrm{normal}$ range) \\
DHE-SO4 & $10 \mu \mathrm{g} / \mathrm{dL}(33.6-249 \mathrm{normal}$ range) \\
\hline AST-ALT-ALP-GGT were within normal ranges.
\end{tabular}

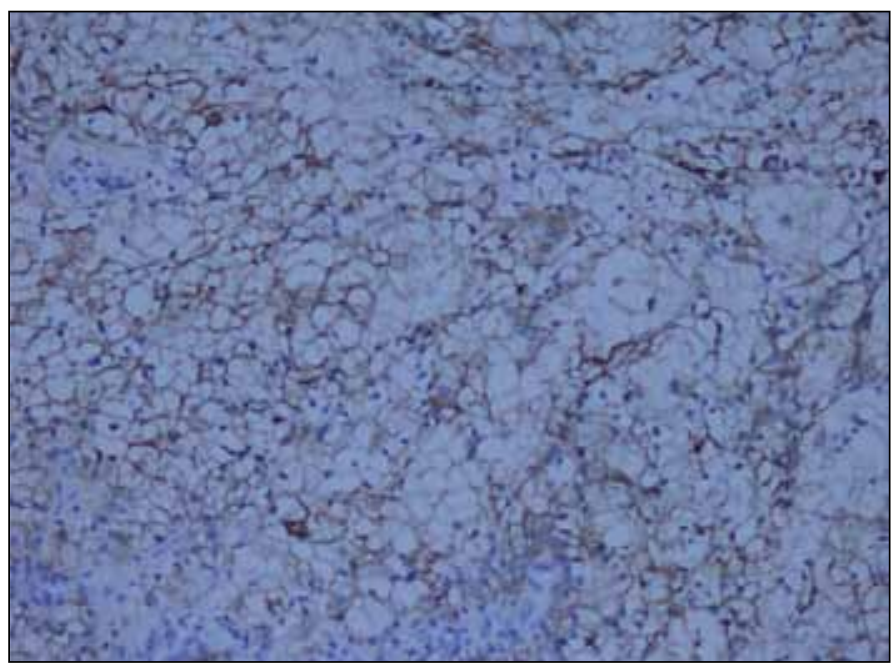

Fig. 9. Immunohistochemistry showing, renal cell carcinoma (RCC) (+), (RCCX200), metastatic mass.

who were found to have adrenal lesion on CT, MRI, or PET/ $\mathrm{CT} .{ }^{11}$ In the present case, a progressively growing adrenal metastatic lesion found in MRI and PET/CT was hormonally inactive. The mean time to metachronous metastasis was 96 months. This is nearly 2 times higher than the time frame described in the literature. Furthermore, the patient did not have any of the risk factors identified for adrenal metastasis. Minimally invasive laparoscopic or robotic surgical procedures are applicable in practice and safe options in patients who develop contralateral metachronous metastasis after radical nephrectomy. ${ }^{12}$

Although adrenal sparing radical nephrectomy is a standard procedure, it should not be preferred in the presence of suspicious adrenal lesions detected by imaging methods.

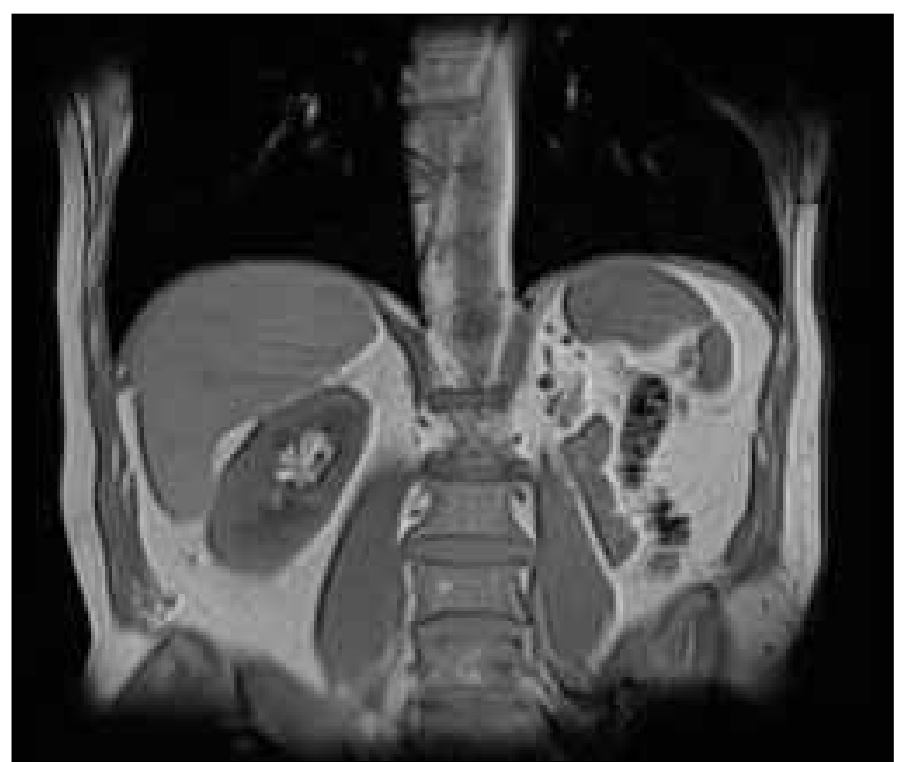

Fig. 10. Magnetic resonance imaging. The coronal reconstruction shows of the patient (12 months of follow-up). 
Adrenalectomy is particularly recommended in this group of patients. Some cases with ipsilateral metastasis are thought to be associated with underdetection of metastasis in the adrenal tissue. Intraoperative biopsy can be helpful when deciding on adrenalectomy in such circumstances. ${ }^{13}$ The main problem for the patients is the determination of a metastasis treatment strategy in solitary adrenal tissue. This is due to the fact that surgical intervention in the single existing adrenal gland will induce the risk developing iatrogenic Addison's disease. This is a more challenging and complex clinical entity. The management of contralateral metachronous adrenal metastasis occurring in patients who underwent radical nephrectomy together with ipsilateral adrenalectomy is extremely difficult. The diagnosis, surgical technique, perioperative decision process, and postoperative follow-up constitute the management steps of this challenging clinical entity. The need of mineralocorticoid and glucocorticoid replacement must be planned prior to surgery with regard to the possible development of Addison's disease. The intraoperative examination of the frozen sections of the mass and adrenal tissue will guide surgical treatment. Partial adrenalectomy is the ideal treatment method because surgical intervention to spare a portion of the adrenal tissue for the patient may prevent the occurrence of other comorbid conditions. Adrenalectomy is inevitable if this is not possible. The present case was diagnosed with iatrogenic Addison's disease following adrenalectomy, and lifelong mineralocorticoid and glucocorticoid replacement was initiated.

\section{Conclusion}

Currently, the adrenalectomy is not a part of the radical nephrectomy procedure. It has been shown to have no contribution to survival. The diagnosis and treatment of metachronous contralateral adrenal metastasis constitute an important oncological problem in patients operated due to RCC. It is of particular importance to detect hormonal activity of the metastatic adrenal masses. Minimally invasive procedures should be considered and planned if adrenalectomy is envisaged. In cases where adrenalectomy is inevitable, the decision must be based on intraoperative biopsy due to the fact that the necessity of using lifelong mineralocorticoids and glucocorticoids in patients with iatrogenic Addison's disease and without adrenal tissue may add endocrinologic problems to oncologic issues.
Competing interests: Dr. Ozturk and Dr. Karaaslan declare no competing financial or personal interests.

This paper has been peer-reviewed.

\section{References}

1. Lau WK, Zincke H, Lohse CM, et al. Contralateral adrenal metastasis of renal cell carcinoma: treatment, outcome and a review. BJU Int 2003;91:775-9. http://dx.doi.org/10.1046/j.1464-410X.2003.04237.x

2. Bhat $S$. Role of surgery in advanced/metastatic renal cell carcinoma. Indian I Urol 2010;26:167-76. http://dx.doi.org/10.4103/0970-1591.65381

3. Koutalellis GE, Felekouras E, Evangelou C, et al. Renal cell carcinoma with bilateral synchronous adrenal gland metastases: A case report. Cases J 2009;2:7298. http://dx.doi.org/10.4076/1757-1626$2-7298$

4. Levy DA, Slaton JW, Swanson DA, et al. Stage specific guidelines for surveillance after radical nephrectomy for local renal cell carcinoma. J Urol 1998;159:1163-7. http://dx.doi.org/10.1016/S0022$5347(01) 63541-9$

5. Kuczyk M, Munch T, Machtens $S$, et al. The need for routine adrenalectomy during surgical treatment for renal cell cancer: the Hannover experience. BJU Int 2002;89:517-22. http://dx.doi.org/10.1046/ i.1464-410X.2002.02671.x

6. Lane BR, Tiong HY, Campbell SC, et al. Management of the adrenal gland during partial nephrectomy. J Urol 2009;181:2430-6. http://dx.doi.org/10.1016/i.juro.2009.02.027

7. Kobayashi T, Nakamura E, Yamamoto S, et al. Low incidence of ipsilateral adrenal involvement and recurrences in patients with renal cell carcinoma undergoing radical nephrectomy: A retrospective analysis of 393 patients. Urology 2003;62:40-5. http://dx.doi.org/10.1016/S0090-4295(03)00247-4

8. Gill IS, MCClennan BL, Kerbl K, et al. Adrenal involvement from renal cell carcinoma: Predictive value of computerized tomography. J Urol 1994;152:1082-5.

9. Alt AL, Boorijan SA, Lohse CM, et al. Survival after complete surgical resection of multiple metastases from renal cell carcinoma. Cancer 2011;117:2873-82. http://dx.doi.org/10.1002/cncr.25836

10. Karam JA, Wood CG. The role of surgery in advanced renal cell carcinoma: cytoreductive nephrectomy and metastasectomy. Hematol Oncol Clin North Am 201 1;25:753-64. http://dx.doi.org/10.1016/j. hoc.2011.05.002

11. Sancho JJ, Triponez F, Montet $X$, et al. Surgical management of adrenal metastases. Langenbecks Arch Surg 2012;397:179-94. http://dx.doi.org/10.1007/s00423-011-0889-1

12. Abel $\mathrm{EJ}$, Karam JA, Carrasco A, et al. Laparoscopic adrenalectomy for metachronous metastases after ipsilateral nephrectomy for renal-cell carcinoma. J Endourol 2011;25:1323-7. http://dx.doi.org/10.1089/ end.2011.0066

13. Tsui KH, Shvarts 0 , Smith RB, et al. Prognostic indicators for renal cell carcinoma: A multivariate analysis of 643 patients using the revised 1997 TNM staging criteria. J Urol 2000;163:1090-5. http://dx.doi. org/10.1016/S0022-5347(05)67699-9

Correspondence: Dr. Hakan Öztürk, Basmane Hospital of Sifa University, Fevzipasa Boulevard No: 172/2, 35240, Basmane-Konak-lzmir/Turkey; drhakanozturk@yahoo.com.tr 